\title{
Impact of maternal dietary lipids on human health
}

\author{
Philippe Guesnet ${ }^{1, *}$, Corinne Marmonier ${ }^{2}$, Constance Boyer ${ }^{2}$ and Bernadette Delplanque ${ }^{3}$ \\ 1 PG Consulting, Bures sur Yvette, France \\ ${ }^{2}$ Nutrition and Health Research Department, CNIEL, Paris, France \\ ${ }^{3}$ Institut des Neurosciences Paris-Saclay (Neuro-PSI), Orsay, France
}

Received 29 March 2018 - Accepted 30 March 2018

\begin{abstract}
During the perinatal period, maternal dietary polyunsaturated fatty acids (PUFA) ensure optimal infant development. Observational studies on cognitive and visual development reported that a specific deficit intake in n-3 PUFA in pregnant women was associated with a reduction in visual acuity in 2months-old infants. Moreover, a low docosahexaenoic acid (DHA) content associated with a high level of n6 PUFA in breast milk was negatively associated with the degree of cognitive development in 6-years-old children. As regards to adipose tissue development, only observational human data agree with the hypothesis that excessive dietary intakes of n-6 PUFA compared with n-3 PUFA could promote the development of adipose tissue and obesity. With regard to immune system development, observational and clinical studies suggest that long-chain n-3 PUFA consumption during pregnancy may prevent the incidence of allergic diseases in children. Lastly, specific association between the maternal ingestion of food groups and the infant health has been studied mainly on allergic outcomes (fish, dairy products). Nutritional recommendations for PUFA intake in pregnant and lactating women were mainly based on brain development data, corresponding to breast milk levels of $10 \%$ of total fatty acids for linoleic acid, $1.5 \%$ for $\alpha$-linolenic acid and $0.4 \%$ for DHA.
\end{abstract}

Keywords: allergic diseases / dairy products / breast milk / brain development / maternal nutrition / obesity / polyunsaturated fatty acids (PUFA)

Résumé - Nutrition lipidique périnatale et santé de l'Homme. L'apport en acides gras polyinsaturés (AGPI) de l'alimentation maternelle participe au développement optimal du nourrisson et de l'enfant. Les études d'observation rapportent qu'un déficit spécifique d'apport alimentaire en AGPIn-3 pendant la grossesse est associé à une réduction du niveau d'acuité visuelle chez l'enfant à l'âge de 2 mois, et que le développement cognitif des enfants à l'âge de 6 ans est associé négativement avec une teneur faible en AGPI n-3 et élevée en AGPIn-6 dans le lait maternel. Elles montrent également qu'un déséquilibre du métabolisme maternel des AGPI en faveur de celui de la série n-6 par rapport aux n-3, favorise le développement du tissu adipeux et de l'obésité chez le jeune. Pour le développement du système immunitaire, les études d'observation et cliniques suggèrent que la consommation d'AGPI n-3 à longue chaîne pendant la grossesse peut prévenir l'incidence des maladies allergiques de l'enfant. Des données sont également disponibles concernant des classes d'aliments (poisson, produits laitiers) et l'incidence des manifestations allergiques. Les recommandations nutritionnelles destinées à la femme enceinte et allaitante s'appuient sur les données du développement cérébral, et correspondent dans le lait maternel à des teneurs d'environ $10 \%$ des acides gras totaux pour l'acide linoléique, $1,5 \%$ pour l'acide $\alpha$-linolénique et $0,4 \%$ pour le DHA.

Mots clés : acides gras polyinsaturés (AGPI) / développement cérébral / lait maternel / nutrition maternelle / maladies allergiques / obésité / produits laitiers

\footnotetext{
*Correspondence: guesnet07@gmail.com
} 


\section{Introduction}

During the perinatal period of development, lipids of the maternal diet are of great importance since they exert significant effects on the development of the fetus and the infant, involving the cerebral and visual functions (Guesnet et al., 2013), but also on the incidence of inflammatory pathologies in infant and child (asthma, allergic diseases) (Miles and Calder, 2017). In the longer term, they may be at the origin of metabolic disturbances that will perpetuate throughout life, favoring in children and adults the emergence of pathologies such as obesity and its associated metabolic complications (Koletzko, 2016). Human studies in neonatal nutrition were conducted in order to determine the impact of maternal fatty acid dietary intake during pregnancy and lactation. The aim of this review is to provide a quick overview of the knowledge gained about the impact of maternal lipid nutrition during pregnancy and lactation, and more specifically of $n-6$ and $n-3$ polyunsaturated fatty acids (PUFA) on the fatty acid levels in maternal and infant blood and plasma lipids, as well as on the fatty acid composition of breast milk, and on the development and health of infants and children. Moreover, specific association between the maternal ingestion of food groups and the infant health is presented in order to evaluate the impact of maternal fish and dairy fat consumption on allergic outcomes, fish being the main source of dietary longchain n-3 PUFA and dairy fats a primary source of dietary lipids consumed in occidental population.

\section{Maternal PUFA intake and PUFA levels in mother and infant blood, and in human milk}

Five major PUFA exert crucial biological functions in humans during the perinatal period of active cellular membrane development taking place from the later part of pregnancy until the early infancy: linoleic acid (LA, 18:2n-6) and $\alpha$-linolenic acid (ALA, 18:3n-3), the respective precursors of the $n-6$ and n-3 series, and three long-chain (LC) derivatives, arachidonic acid for the $n-6$ series (AA, 20:4n-6), and eicosapentaenoic (EPA, 20:5n-3) and docosahexaenoic (DHA, 22:6n-3) acids for the n-3 series. During pregnancy, they are transported from maternal circulation to the fetus across the placenta, but LC-PUFA such as AA and DHA are more selectively and actively transferred than PUFA precursors as evidenced by their higher levels in the fetal than in the maternal plasma (Crawford et al., 1981). Therefore, increasing the maternal dietary intake of DHA during the last trimester of pregnancy allows to elevate the DHA content in maternal plasma and red blood cells and consequently the DHA status of the developing fetus (concentration in cord blood) (Connor et al., 1996) (Fig. 1). In contrast, maternal dietary intake of ALA is less efficient to elevate the DHA status of the fetus due to low maternal conversion of ALA to DHA. During lactation, both dietary LC-PUFA and PUFA precursors are transferred into breast milk lipids. Breast milk PUFA are also derived from their mobilization from adipose tissues which have been partly constituted before and during pregnancy. Furthermore, it has been shown that LA milk content is more closely correlated to that of the adipose tissue than that of the maternal diet (Martin et al., 1993): two-thirds

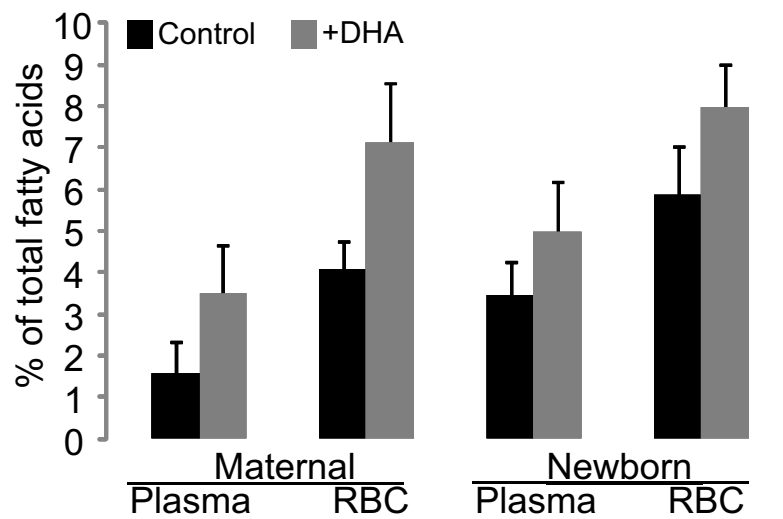

Fig. 1. Impact of DHA supplementation during pregnancy on the DHA level of the plasma and red blood cells (RBC) at delivery in mothers and newborn infants (Connor et al., 1996).

At 24 to 30 weeks gestation, pregnant women received or not a DHA supplementation until 34 weeks gestation $(+1.1 \mathrm{~g} / \mathrm{d})$.

derivate from mobilization of adipose tissue and one-third directly from the maternal diet. Therefore, PUFA concentrations are highly dependent on maternal intakes during both pregnancy and lactation periods. The LA content of human milk varies from a factor of 1 to 6 and can reach for about $30 \%$ of total fatty acids in USA (Ailhaud et al., 2006) (Fig. 2, Part A), and more than $30 \%$ in strict vegetarian women consuming no animal products (Sanders et al., 1978; Burdge et al., 2017). In Western countries during the last 50 years, LA mean content has significantly increased in human milk due to specific marked changes in the nature of lipid consumed, and notably in USA ranging from less than $5 \%$ of total fatty acids in the $1950 \mathrm{~s}$ to more than 15-25\% today (Ailhaud et al., 2006) (Fig. 2, Part A). With regard to n-3 PUFA, variations are even more marked since ALA and DHA contents vary respectively from 0.5 up to $6 \%$ in women supplemented with linseed oil, and from $<0.1 \%$ to more than $1.5 \%$ in women supplemented with fish oil (Gibson et al., 1997) or in populations consuming large amount of seafood (Innis and Kuhnlein, 1988) (Fig. 2, Part A). Today in France, LA averages $10 \%$ of total fatty acids in human milk and ALA $0.9 \%$, ending with a ratio LA/ALA close to 12 (Mazurier et al., 2017). Two-thirds of long-chain n3 PUFA are in the form of docosahexaenoic acid (22: $6 n-3$, DHA), which represents $0.2-0.3 \%$ of total fatty acids.

Lastly, human milk contains high concentrations of saturated fatty acids (SFA, $50 \%$ of total fatty acids) mainly as the form of palmitic acid (16:0, 23\%), myristic acid (14:0, $8 \%)$ and medium chain fatty acids $(8: 0-12: 0,9 \%)$ (Guesnet et al., 2013). It also contains high levels of monounsaturated fatty acids (MUFA), accounting for about $40 \%$ of total fatty acids, mostly as oleic acid (18:1n-9, 34\%). Milk levels of SFA and MUFA are also modified by maternal dietary intake but to a lesser extent than PUFA. Nevertheless, SFA and palmitic acid levels can be reduced by half in the milk of vegetarian women consuming little saturated animal fats. The impact of such specific decrease in milk palmitic acid on the child's health is unknown. This fatty acid is involved in many crucial functions and it might be essential during development (Innis, 2016). LA concentration in human milk could be significantly decreased in lactating women consuming high amounts of 


\section{A - Minimal and maximal values of PUFA contents in human milk}
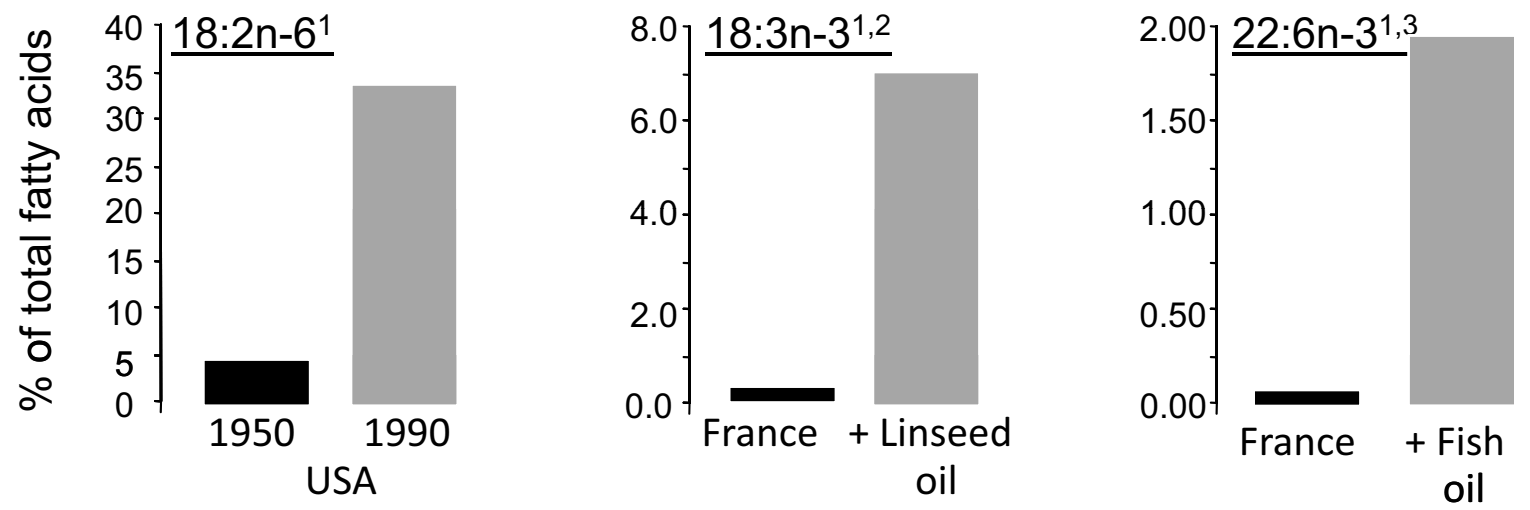

\section{B - Maternal dietary intake of PUFA and content in the human milk}
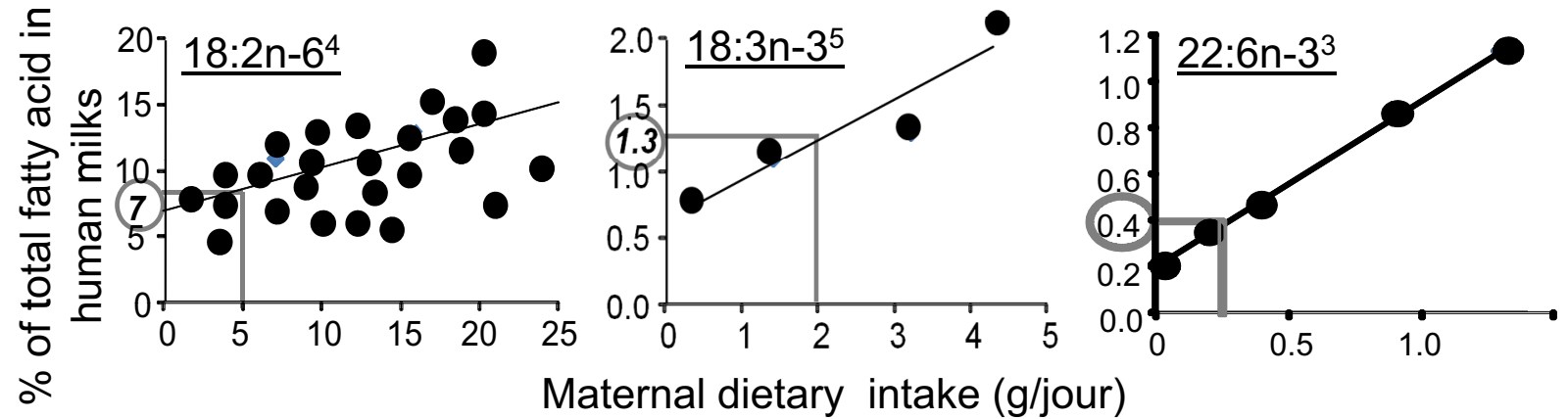

Fig. 2. Variation of polyunsaturated fatty acid (PUFA) contents in human milk (Part A) and influence of maternal PUFA intake during lactation on their contents in human milk (Part B).. Ailhaud et al., 2006; ${ }^{2}$ François et al., 2003; ${ }^{3}$ Gibson et al., 1997; ${ }^{4}$ Martin et al., $1993 ;{ }^{5}$ Mazurier et al., 2017.

saturated animal fats (such as butter and dairy fats) compared to women with high consumption of vegetable oils (Yahvah et al., 2015).

\section{Maternal PUFA intake: infant cognitive and visual development}

DHA is highly concentrated in cerebral and retinal membranes since it takes account for about $25 \%$ of total fatty acids in the human cerebral cortex and more than $30 \%$ in the whole retina. The accretion of DHA in human brain phospholipids occurs primarily during the fetal brain growth spurt of active neurogenesis and cell maturation (i.e. the last trimester of pregnancy), and the early postnatal period of development of intense synaptogenesis (first two years of life) (Alessandri et al., 2004). Animal models of chronic dietary n3 PUFA deficiency applied during all the period of pregnancy and lactation induce in the young a marked decline of the incorporation of DHA in brain and retina membranes, and significant alterations in behavioral performances of learning and visual functions which persist in adulthood (Alessandri et al., 2004). Restoration of normal brain DHA contents after the period of development is possible by fish oil feeding, but some alterations in visual parameters remain abnormal
(Anderson et al., 2005). In agreement with these animal data, clinical studies conducted in term infants fed with low n3 PUFA formulas have reported significant decrease in brain DHA concentration and alterations in visual acuity at 4 months and 3 years of age (Farquharson et al., 1995; Uauy et al., 2001).

For the infant brain and retina development, most of the human studies have been focused on PUFA and more specifically on n-3 LC-PUFA. With regard to the pregnancy period, several observational and clinical studies have specifically evaluated the association of maternal n-3 PUFA status and dietary intake with the infant neurodevelopment outcomes. Epidemiological data measuring blood DHA concentrations in women at the end of pregnancy and in infants at birth (cord) have generally reported positive associations between DHA status, and cognitive and visual functioning in infants aged from 2 days to 7 years (reviewed in Gould et al., 2016). Randomized controlled trials have mainly investigated the effect of DHA supplementation during the last half of pregnancy on infant and child cognitive and visual development from several months of age until the age of 12 years. They reported controversial results due to several experimental limitations such as too small numbers of enrolled mothers and their infants $(<100)$ and uncontrolled potential biases (reviewed in Gould et al., 2016). One large randomized controlled trial was conducted on 2399 pregnant women 
receiving a dietary supplement of $800 \mathrm{mg}$ DHA/day until delivery, and their children were followed from birth until the age of 7 years (the DOMInO trial) (Gould et al., 2016). Globally, data from this trial did not show clear effects of DHA supplementation during pregnancy on neurodevelopment outcomes in 18-months-old infants and on general cognitive functioning in 4-years-old children. However, 4years-old children whose mothers received the DHA supplement had lower mild delayed cognitive development. In all these studies, it was hypothesized that the studied populations of pregnant women consumed typical Western diets high in n-6 PUFA and low in n-3 PUFA. However, no PUFA maternal dietary intakes were assessed before DHA supplementation, women who consumed non-adequate intakes of n-3 PUFA not being distinguished from women consuming adequate intakes. In other series of observational and clinical studies conducted in Canada (Innis and Elias, 2003; Innis and Friesen, 2008; Mulder et al., 2014), daily usual intakes of individual n-6 and n-3 PUFA were quantified in pregnant women and then validated by the measurement of PUFA levels in plasma phospholipids (Innis and Elias, 2003). During the last trimester of pregnancy, $40 \%$ were considered as DHA-deficient since they consumed a quantity of DHA lower than the total amount deposited in the fetus during this period (Innis and Friesen, 2008). Moreover, the DHA deficiency was amplified in some pregnant women because their ALA dietary intake was low and associated with a high LA/ALA ratio unfavorable for the DHA synthesis. Clinical data showed an increased risk of lower visual acuity in 2-months-old infants and of lower language development in 18-months-old infants whose mothers consumed these unbalanced diets, in comparison to infants whose mothers have received a DHA supplementation $(400 \mathrm{mg} / \mathrm{d})$ until delivery (Innis and Friesen, 2008; Mulder et al., 2014).

As regards to the period of lactation, several observational studies have reported positive associations between visual and cognitive development in term gestation breastfed infants and DHA amounts in their red blood cell and in mothers' milk (reviewed by Innis, 2014). A recent large study reported long-term impact since the consumption of breast milk with high LA-low DHA contents was associated with a significant reduction in intelligence quotient in children at age 5-6 years (Bernard et al., 2017a). This reduction was no longer observed when low-DHA breast milk contained low level of linoleic acid or when breast milk contained high DHA-high LA contents. This suggests that the milk content of DHA as well as the ratio LA/ALA can both significantly influence the cognitive development of infants and children. This study suggested unfavorable effect of feeding newborn infants with high LA and low DHA human milk, but needs to be replicated by measuring together maternal dietary PUFA intakes. Few randomized clinical studies have been conducted using DHA supplementation ranging from 0.2 to $1.3 \mathrm{~g} / \mathrm{d}$, which showed no impact, positive or negative impact on cognitive or visual outcomes in breastfed infants and in children until the age of 5 years (reviewed by Jensen and Lapillonne, 2009, and Innis, 2014). Once again, basal maternal dietary PUFA intakes were not measured in these clinical studies which did not allow to draw clear conclusions.

\section{Maternal PUFA intake, obesity and allergic diseases}

\subsection{Obesity}

Adipose tissue development in humans is particularly active during the perinatal period. It involves an increase of both number (differentiation and proliferation) and size (hypertrophy) of adipocytes, and it is sensitive to lipid nutrition. Based on in vitro and in vivo animal studies, it has been hypothesized that a disequilibrium of PUFA metabolism in favor of the $\mathrm{n}-6$ series (due to imbalance of maternal dietary intakes of PUFA precursors [LA/ALA ratio] and of their major long-chain $[\mathrm{AA} / \mathrm{EPA}+\mathrm{DHA}$ ratio]), could increase the risk of excessive adipose tissue development and might be an important parameter for the increased prevalence of overweight and obesity in children and adults in Western countries (Ailhaud et al., 2006; Ailhaud et al., 2008). Indeed, in rodent models, high LA/ALA ratio $(>25)$ in the maternal diet increased the fat mass at weaning until adulthood (Massiera et al., 2003). It also raised tissue and milk contents of arachidonic acid while decreasing EPA and DHA, which in turn increased prostacyclin production and then the signaling pathways favoring adipogenesis. Balancing the LA/LNA dietary ratio by a reduction to value of 2 suppresses both the increased fat mass and n-6 PUFA levels in tissues and milk. Lastly, data on high dietary intakes of EPA and DHA during the entire period of growth suggested an inhibitory effect on adipose tissue development in young and adult rodents, though data were inconsistent when EPA-DHA supplementation was strictly achieved during the perinatal period (pregnancylactation) (Hauner et al., 2013).

In humans, several observational studies conducted on a large number of mother-child pairs have reported that adiposity in children at 3 to 6 years of age was positively correlated with LA and n-6PUFA levels and the AA/ $\mathrm{EPA}+\mathrm{DHA}$ ratio in maternal plasma during pregnancy (third trimester), and with the AA/EPA+DHA ratio in their blood at birth (cord) (Donahue et al., 2011; Moon et al., 2013; Bernard et al., 2017b). In the Generation R study, similar results were observed with maternal n-3 and n-6 PUFA concentrations in plasma at mid-pregnancy for total body fat mass and preperitoneal fat in infants at 6 years of age (Vidakovic et al., 2016). With regards to the period of lactation, only few studies have investigated the relation between breast milk PUFA concentrations and the development of adiposity in children who were breastfed. Similar trends were observed, such as a significant increase in body fat mass in 4-months-old breastfed infants whose mother's milk has high ratio of AA/ EPA+DHA (Rudolph et al., 2017), and a negative association between milk DHA content and the fat mass in infants aged from 2 to 7 years (Pedersen et al., 2012). Lastly, few randomized controlled trials have been conducted during pregnancy and/or lactation and exclusively by supplementing the maternal diet with long-chain n-3 PUFA between 0.2 to $1.2 \mathrm{~g} / \mathrm{d}$ (reviewed in Hauner et al., 2013). Results on infant body composition are inconsistent because the timing and duration of the PUFA supplementation were quite variable among studies and no data on maternal fatty acid intake at baseline were reported, which does not allow to determine a possible PUFA disequilibrium in these populations of women. 


\subsection{Allergic diseases}

The development of the immune system takes place during the pre- and post-natal periods of development in humans and is modulated by the maternal nutrition. It is admitted that a high ratio of $n-6 / n-3$ PUFA exerts negative effect on immune cell functioning and inflammation, and therefore on the risk of allergic diseases. This effect involved notably the increased production of pro-inflammatory eicosanoids derived from n6 PUFA (AA), at the expense of anti-inflammatory proresolving mediators produced from n-3 long-chain PUFA (EPA and DHA) (Miles and Calder, 2017). As regards to pregnancy, observational studies have suggested a protective association of the consumption of n-3 long-chain PUFA by the mothers on the risk of allergic manifestations in infants and children, but globally results are not clear (Miles and Calder, 2017). Randomized controlled trials supplementing the diet of pregnant women with fish oil at high doses of EPA+DHA (from $0.9 \mathrm{~g} / \mathrm{d}$ to $3.7 \mathrm{~g} / \mathrm{d}$ ) reported more convincing protective impact on asthma and atopic dermatitis in the young infant. Indeed, the supplementation of the pregnant women diet with $2.4 \mathrm{~g} / \mathrm{d}$ EPA+DHA from the $24^{\text {th }}$ week of pregnancy until the delivery was associated with a $30 \%$ decrease of the risk of asthma in infants until 5-years-old (Bisgaard et al., 2016). Regarding the period of lactation, the association with longchain n-3 PUFA and/or fish consumption with the incidence of allergic diseases is not clearly established both for families at risk of allergies and those that are not at risk (Netting et al., 2014). However, the results are more convincing in youngest infants. Thus, in a study conducted on one hundred motherinfant pairs aged 6 to 12 months, an association was observed with the PUFA content of breast milk, which was positive with the incidence of asthma-like symptoms when mother's breast milk contained high level of n-6 PUFA, and negative with the incidence of atopic diseases for high n-3 PUFA level (SotoRamírez et al., 2012).

\section{Maternal consumption of dairy fats and infant health}

Numerous epidemiological studies have been conducted to determine whether dietary patterns (Mediterranean diet, for example) or the ingestion of specific food groups by the mother during pregnancy and lactation were associated with health outcomes in infant, and notably allergy and atopic diseases (reviewed in Netting et al., 2014). Globally, there is no consistent association between maternal nutrition during either pregnancy or breastfeeding and the incidence of these diseases (Netting et al., 2014). For example, observational study data suggested a protective effect of the maternal fish consumption during either pregnancy via its high content of long-chain n3 PUFA, but results lack of consistency. As regards to the consumption of dairy food products and of dairy lipids and the period of pregnancy, 3 observational studies reported semiquantitative data on the maternal consumption of both butter, milk and milk products, and individual fatty acids (Lumia et al., 2011; Nwaru et al., 2012; Tuokkola et al., 2016). Despite large variations in the levels of consumption of dairy fats and fatty acids by the mother (butter: from 4 to $20 \mathrm{~g} / \mathrm{d}$; milk and milk derivatives: from $550 \mathrm{~g}$ to $1100 \mathrm{~g} / \mathrm{d}$ ), results were inconclusive for an effect on the risk of allergy and atopic diseases in infants, whereas a protective effect was noted for cow's milk allergy (Tuokkola et al., 2016). The study of the consequences of dairy food products and dairy lipid consumption by the lactating woman have been exclusively focused on the incidence of atopic diseases (Thijs et al., 2011; Lumia et al., 2012) and one study has investigated the relation with the fatty acid concentration in human milk (Thijs et al., 2011). First, compared to a population of lactating women that rarely consumed dairy fats, the daily consumption of 4 dairy products + butter reduced significantly the breast milk contents of LA and ALA, without modifying their relative proportion (LA/ALA ratio). It also significantly increased saturated fatty acid contents as well as levels of fatty acid markers of dairy fats (vaccenic and rumenic acids). Only the study of Thijs et al. (2011), conducted on 310 mother-infant pairs, has reported a significant protective effect of dairy food consumption since the concentration of vaccenic and rumenic acids in women's milk was negatively associated with the incidence of eczema and atopic dermatosis in 2-years-old infants. Moreover, a high breast milk content of long-chain n3 PUFA was also predictive of a lower prevalence of these two diseases. Since dairy fats are low in LA, the protective effect of a high dairy food consumption could result in a rebalancing of the ratio of $n-6$ to $n-3$ PUFA by reducing the high LA maternal intake consequently to a decreased consumption of LA-rich margarines and vegetable oils (Jonsson et al., 2016).

\section{Conclusions}

Animal and human observational studies have well demonstrated that n-3 PUFA and DHA in the maternal diet are critically important for the development of cognition and vision of infants. However, randomized controlled trials using DHA supplementation have reported controversial data which could result from uncontrolled confounding factors. Among them, large variations between infants in their own potential of development were evidenced for visual acuity at the age of 2 months (Innis and Friesen, 2008). As regards to obesity and allergy diseases, further observational and clinical studies are needed to verify:

- whether a high maternal n-6 to n-3 ratio (diet, breast milk), due to a non-adequate low consumption of n-3 PUFA associated or not with a high LA consumption, could promote the prevalence of obesity and/or allergy diseases in infants and children;

- whether a prevention could be possible by a maternal dietary n-3 PUFA supplementation or by changing food dietary patterns in pregnant and lactating women to rebalance the ratio of $n-6$ to $n-3$ PUFA.

Thus, further human observational studies on fish and dairy fat consumption using precise quantitative data would help clarifying the effects of these foods during the perinatal period. This is of importance since most of current human diets in the Western industrialized world are generally low in n-3 PUFA, mainly as the form of long-chain EPA and DHA (Sioen et al., 2017), with some of them which are also high in LA as evidenced in USA (Ailhaud et al., 2006). 
Meanwhile, specific recommended dietary intakes (RDIs) for PUFA have been published for women during pregnancy and lactation. The French Agency for Food, Environmental and Occupational Health \& Safety recommended for pregnant and lactating women $4.6 \mathrm{~g} / \mathrm{d} \mathrm{LA}$ and $1.8 \mathrm{~g} / \mathrm{d}$ ALA and $5.0 \mathrm{~g} /$ $\mathrm{d}$ LA and $2.0 \mathrm{~g} / \mathrm{d} \mathrm{LA}$, respectively, and a RDI of $250 \mathrm{mg} / \mathrm{d}$ for DHA (ANSES, 2011). These guidelines would allow to reach about $10 \%$ of total breast milk fatty acids for LA, $1.5 \%$ for ALA and $0.4 \%$ for DHA (Fig. 2, Part B).

\section{In Memoriam}

In Memoriam of Dr. Sheila Innis (University Of British Columbia Department Of Paediatrics, Vancouver, Canada) who was a pioneer researcher in the field of $n-3$ PUFA and brain development, and conducted many clinical studies relating maternal diet to placental and breast milk fat transfer, as well as the impact of diet in child development and health (http://goedomega3.com/index.php/the-goed-current-editori als/in-memoriam-of-dr-sheila-innis).

\section{References}

Ailhaud G, Massiera F, Weill P, Legrand P, Alessandri JM, Guesnet P. 2006. Temporal changes in dietary fats: role of $n-6$ polyunsaturated fatty acids in excessive adipose tissue development and relationship to obesity. Prog Lipid Res 45: 203-236.

Ailhaud G, Guesnet P, Cunnane SC. 2008. An emerging risk factor for obesity: does disequilibrium of polyunsaturated fatty acid metabolism contribute to excessive adipose tissue development? Br J Nutr 100: 461-470.

Alessandri JM, Guesnet P, Vancassel S, et al. 2004. Polyunsaturated fatty acids in the central nervous system: evolution of concepts and nutritional implications throughout life. Reprod Nutr Dev 44: 509-538.

Anderson GJ, Neuringer M, Lin DS, Connor WE. 2005. Can prenatal N-3 fatty acid deficiency be completely reversed after birth? Effects on retinal and brain biochemistry and visual function in rhesus monkeys. Pediatr Res 58: 865-872.

Bernard JY, Armand M, Peyre H, et al. 2017a. EDEN Mother-Child Cohort Study Group (Étude des Déterminants pré- et postnatals précoces du développement et de la santé de l'Enfant). Breastfeeding, polyunsaturated fatty acid levels in colostrum and child intelligence quotient at age 5-6 Years. J Pediatr 183: 43-50.

Bernard JY, Tint MT, Aris IM, et al. 2017b. Maternal plasma phosphatidylcholine polyunsaturated fatty acids during pregnancy and offspring growth and adiposity. Prostaglandins Leukot Essent Fatty Acids 121: 21-29.

Bisgaard H, Stokholm J, Chawes BL, et al. 2016. Fish oil-derived fatty acids in pregnancy and wheeze and asthma in offspring. $N$ Engl J Med 375: 2530-2539.

Burdge GC, Tan SY, Henry CJ. 2017. Long-chain n-3 PUFA in vegetarian women: a metabolic perspective. J Nutr Sci 23: e58. DOI: $10.1017 /$ jns.

Connor WE, Lowensohn R, Hatcher L. 1996. Increased docosahexaenoic acid levels in human newborn infants by administration of sardines and fish oil during pregnancy. Lipids 31: S183-S187.

Crawford MA, Hassam AG, Stevens PA. 1981. Essential fatty acid requirements in pregnancy and lactation with special reference to brain development. Prog Lipid Res 20: 31-40.
Donahue SM, Rifas-Shiman SL, Gold DR, Jouni ZE, Gillman MW, Oken E. 2011. Prenatal fatty acid status and child adiposity at age 3 y: results from a US pregnancy cohort. Am J Clin Nutr 93: 780-788.

Farquharson J, Jamieson EC, Abbasi KA, Patrick WJ, Logan RW, Cockburn F. 1995. Effect of diet on the fatty acid composition of the major phospholipids of infant cerebral cortex. Arch Dis Child 72: 198-203.

Francois CA, Connor SL, Bolewicz LC, Connor WE. 2003. Supplementing lactating women with flaxseed oil does not increase docosahexaenoic acid in their milk. Am J Clin Nutr 77: 226-233.

French Agency for Food, Environmental and Occupational Health \& Safety (ANSES). 2011. Actualisation des apports nutritionnels conseillés pour les acides gras. Rapport d'expertise collective. Disponible sur https://www.anses.fr/fr/system/files/NUT2006 sa0359Ra.pdf (dernière consult. : octobre 2017).

Gibson RA, Neumann MA, Makrides M. 1997. Effect of increasing breast milk docosahexaenoic acid on plasma and erythrocyte phospholipid fatty acids and neural indices of exclusively breast fed infants. Eur J Clin Nutr 51: 578-584.

Gould JF, Treyvaud K, Yelland LN, et al. 2016. Does n-3 LCPUFA supplementation during pregnancy increase the IQ of children at school age? Follow-up of a randomised controlled trial. BMJ Open 6: e011465.

Guesnet P, Ailhaud G, Delplanque B, Alessandri JM. 2013. Place des lipides dans l'alimentation du nourrisson. OCL 2: 79-87.

Hauner H, Brunner S, Amann-Gassner U. 2013. The role of dietary fatty acids for early human adipose tissue growth. Am J Clin Nutr 98: 549S-55S.

Innis SM. 2014. Impact of maternal diet on human milk composition and neurological development of infants. Am J Clin Nutr 99: 734S-741S.

Innis SM. 2016. Palmitic acid in early human development. Crit Rev Food Sci Nutr 56: 1952-1959.

Innis SM, Elias SL. 2003. Intakes of essential n-6 and n3 polyunsaturated fatty acids among pregnant Canadian women. Am J Clin Nutr 77: 473-478.

Innis SM, Friesen RW. 2008. Essential n-3 fatty acids in pregnant women and early visual acuity maturation in term infants. $\mathrm{Am} \mathrm{J}$ Clin 87: 548-557.

Innis SM, Kuhnlein HV. 1988. Long-chain n-3 fatty acids in breast milk of Inuit women consuming traditional foods. Early Hum Dev 18: 185-189.

Jensen CL, Lapillonne A. 2009. Docosahexaenoic acid and lactation. Prostaglandins Leukot Essent Fatty Acids 81: 175-178.

Jonsson K, Barman M, Moberg S, et al. 2016. Fat intake and breast milk fatty acid composition in farming and nonfarming women and allergy development in the offspring. Pediatr Res 79: 114-123.

Koletzko B. 2016. Childhood obesity: Current situation and future opportunities. J Pediatr Gastroenterol Nutr 63(Suppl 1): S18-S21.

Lumia M, Luukkainen P, Tapanainen H, et al. 2011. Dietary fatty acid composition during pregnancy and the risk of asthma in the offspring. Pediatr Allergy Immunol 22: 827-835.

Lumia M, Luukkainen P, Kaila M, et al. 2012. Maternal dietary fat and fatty acid intake during lactation and the risk of asthma in the offspring. Acta Paediatr 101: e337-e343.

Martin JC, Bougnoux P, Fignon A, et al. 1993. Dependence of human milk essential fatty acids on adipose stores during lactation. $\mathrm{Am} \mathrm{J}$ Clin Nutr 58: 653-659.

Massiera F, Saint-Marc P, Seydoux J, et al. 2003. Arachidonic acid and prostacyclin signaling promote adipose tissue development: a human health concern? J Lipid Res 44: 271-279. 
Mazurier E, Rigourd V, Perez P, et al. 2017. Effects of maternal supplementation with omega-3 precursors on human milk composition. J Hum Lact 33: 319-328.

Miles EA, Calder PC. 2017. Can early omega-3 fatty acid exposure reduce risk of childhood allergic disease? Nutrients 21, 9(7); pii: E784.

Moon RJ, Harvey NC, Robinson SM, et al.; SWS Study Group. 2013. Maternal plasma polyunsaturated fatty acid status in late pregnancy is associated with offspring body composition in childhood. J Clin Endocrinol Metab 98: 299-307.

Mulder KA, King DJ, Innis SM. 2014. Omega-3 fatty acid deficiency in infants before birth identified using a randomized trial of maternal DHA supplementation in pregnancy. PLoS One 9: e83764.

Netting MJ, Middleton PF, Makrides M. 2014. Does maternal diet during pregnancy and lactation affect outcomes in offspring? A systematic review of food-based approaches. Nutrition 30: 1225 1241 .

Nwaru BI, Erkkola M, Lumia M, et al. 2012. Maternal intake of fatty acids during pregnancy and allergies in the offspring. Br J Nutr 108: 720-732.

Pedersen L, Lauritzen L, Brasholt M, Buhl T, Bisgaard H. 2012. Polyunsaturated fatty acid content of mother's milk is associated with childhood body composition. Pediatr Res 72: 631-636.

Rudolph MC, Young BE, Lemas DJ, et al. 2017. Early infant adipose deposition is positively associated with the n- 6 to n-3 fatty acid ratio in human milk independent of maternal BMI. Int $J$ Obes (Lond) 41: 510-517.
Sanders TA, Ellis FR, Dickerson JW. 1978. Studies of vegans: the fatty acid composition of plasma choline phosphoglycerides, erythrocytes, adipose tissue, and breast milk, and some indicators of susceptibility to ischemic heart disease in vegans and omnivore controls. Am J Clin Nutr 31: 805-813.

Sioen I, van Lieshout L, Eilander A, et al. 2017. Systematic review on n-3 and n-6 polyunsaturated fatty acid intake in European countries in light of the current recommendations - Focus on specific population groups. Ann Nutr Metab 70: 39-50.

Soto-Ramírez N, Karmaus W, Zhang H, et al. 2012. Fatty acids in breast milk associated with asthma-like symptoms and atopy in infancy: a longitudinal study. J Asthma 49: 926-934.

Thijs C, Müller A, Rist L, et al. 2011. Fatty acids in breast milk and development of atopic eczema and allergic sensitisation in infancy. Allergy 66: 58-67.

Tuokkola J, Luukkainen P, Tapanainen H, et al. 2016. Maternal diet during pregnancy and lactation and cow's milk allergy in offspring. Eur J Clin Nutr 70: 554-559.

Uauy R, Hoffman DR, Peirano P, Birch DG, Birch EE. 2001. Essential fatty acids in visual and brain development. Lipids 36: 885-895.

Vidakovic AJ, Gishti O, Voortman T, et al. 2016. Maternal plasma PUFA concentrations during pregnancy and childhood adiposity: the Generation R Study. Am J Clin Nutr 103: 1017-1025.

Yahvah KM, Brooker SL, Williams JE, Settles M, McGuire MA, McGuire MK. 2015. Elevated dairy fat intake in lactating women alters milk lipid and fatty acids without detectible changes in expression of genes related to lipid uptake or synthesis. Nutr Res 35: $221-228$.

Cite this article as: Guesnet P, Marmonier C, Boyer C, Delplanque B. 2018. Impact of maternal dietary lipids on human health. OCL 25(3): D302. 